\title{
Effects of Soil Sterilization on Growth of Angelica sinensis Plant and Soil Microbial Populations in a Continuous Mono-cropping Soil
}

\author{
Xin-Hui Zhang, 1,2,4,5, Duo-Yong Lang ${ }^{6}$ and En-He Zhang ${ }^{2 *}$ \\ ${ }^{1}$ College of Pharmacy, Ningxia Medical University, Yinchuan 750004, China \\ ${ }^{2}$ College of Agronomy, Gansu Agricultural University, Lanzhou 730070, China \\ ${ }^{3}$ Ningxia Engineering and Technology Research Center of Hui Medicine Modernization, Yinchuan 750004, China \\ ${ }^{4}$ Ningxia Collaborative Innovation Center of Hui Medicine, Yinchuan 750004, China \\ ${ }^{5}$ Laboratory of Hui Ethnic Medicine Modernization, Ministry of Education, Yinchuan 750004, China \\ ${ }^{6}$ Laboratory Animal Center, Ningxia Medical University, Yinchuan 750004, China \\ *For correspondence: zhang2013512@163.com; zhangeh@gsau.edu.cn
}

\begin{abstract}
Angelica sinensis (Oliv.) Diels (family Apiaceae) is a perennial herb that has been widely used in Traditional Chinese Medicine. The soil sickness has become one of the major constrains in A. sinensis cultivation. A pot experiment was done to evaluate the role of biological nature in $A$. sinensis soil sickness. The pot experiment include three treatments (i) contol, which represent as the soil in pot taken from spring wheat stands, (ii) AA, which represent as the soil in pot taken from $A$. sinensis stands, (iii) S-AA, which represent as the soil in pot was sterilized by steam at $121^{\circ} \mathrm{C}$ for $4 \mathrm{~h}$ taken from $A$. sinensis stands. Results showed that the plant height, dry weight of aboveground part and roots, root yield and quality, and the activities of SOD and POD in leaves were significantly higher in sterilized replant soil than in non-sterilized replant soil treatment, while the activity of CAT and content of MDA in leaves were declined, which indicated that soil sterilization improved plant haleness and increased the activities of active oxygen scavenging enzymes. The results also demonstrated that soil sterilization can change the number of culturable microbial populations and the species diversity of bacterial functional group. Higher Shannon-Wiener index was found in rhizosphere soils under sterilized soil cropping than that under non-sterilized soil cropping. This suggests that the biological factor played a causal role in the development of $A$. sinensis soil sickness and sterilization of continuous cropping soil could change the composition and structure of soil microbial community, which further promote plant growth and alleviate $A$. sinensis soil sickness. (C) 2016 Friends Science Publishers
\end{abstract}

Keywords: Angelica sinensis; Soil sickness; Culturable microbial population; Growth parameter; Anti-oxidative enzymes

\section{Introduction}

Soil sickness is a reduction in both crop yield and quality, when the same crop or cultivar is grown year after year in the same soil. In general, continuous cropping can affect crop growth and development, decrease yield and quality, and increase disease occurrence (Wu et al., 2009; Zhang et al., 2010; Zhang et al., 2015a). Soil sickness usually occurred in medicinal plant (Yang et al., 2014; Zhang et al., 2015b). Many researches indicated that there were soil physiochemical property disorders, soil microbial community changes and autotoxicity are responsible for the soil sickness (Yu and Matsui, 1994; Yang et al., 2012; Mazzola and Manici, 2012). Previous studies report that soil microflora change is one of the major causes in soil sickness in Cistus ladanifer (Hassan et al., 1989), peach (Benizri et al., 2005), cucumber (Yao et al., 2006), Rehmannia glutinosa (Zhang et al., 2011), Liriope (Zhao et al., 2010) and apple (Yim et al., 2013).
Angelica sinensis (Oliv.) Diels, is a perennial herb belonging to family Apiaceae, and commonly used in Traditional Chinese Medicine since ancient times (Zhang and Cheng, 1989). In addition, $A$. sinensis is widely used as an ingredient in cosmetic and health beverage at present (Chen, 2002; Champakaew et al., 2015). In order to meet its demand, areas of continuous cropped for A. sinensis have been increased dramatically in the last decade. Because of this, growers face serious problems under continuous cropping including growth retardation, plant mortality and Ditylenchus destructor infestation. These reduce not only the root yield but also the quality of $A$. sinensis (Zhang et al., 2009). At present, the soil sickness has become one of the major constrains in $A$. sinensis cultivation.

Previous studies on the causative factors for replanting yield and quality decline mainly focused on autotoxicity (Zhang et al., 2010) and physiological activity (Zhang et al., 2013) in A. sinensis. Moreover, the effect of continuous cropping on soil microbial populations in rhizosphere also

To cite this paper: Zhang, X.H., D.Y. Lang and E.H. Zhang, 2016. Effects of soil sterilization on growth of Angelica sinensis plant and soil microbial populations in a continuous mono-cropping soil. Int. J. Agric. Biol., 18: 458-463 
has been investigated (Zhang et al., 2015b). However, the possible role of soil microflora in $A$. sinensis continuous cropping obstacle remained obscure.

In this study, effect of soil sterilization on growth of $A$. sinensis plants and soil microflora in a continuous monocropping soil was analyzed. The objective was to study the role played by soil microflora in A. sinensis continuous cropping problems.

\section{Materials and Methods}

\section{Soil}

Top loam soil (about $0-30 \mathrm{~cm}$ ) was collected in October 2008 from the Minxian County $\left(103^{\circ} 34^{\prime} \mathrm{E}, 34^{\circ} 27^{\prime} \mathrm{N}\right)$ of Gansu province, China. Twenty samples were taken from $A$. sinensis stands (hereinafter referred to as AA) in which yield declined significantly in $A$. sinensis and from spring wheat (Xihan 1) stands (hereinafter referred to CK) respectively as experimental soil. Three replicates of each soil sample were analyzed for organic matter, $\mathrm{pH}$, total nitrogen $(\mathrm{N})$ content, potassium $(\mathrm{K})$ and phosphorus $(\mathrm{P})$, and available nitrogen $(\mathrm{N})$ and phosphorus $(\mathrm{P})$ concentration. The properties of the AA and CK are shown in Table 1.

The soil samples were screened through a $1 \mathrm{~mm}$ sieve in order to remove plant residues and stones. A part of AA was sterilized by steam at $121^{\circ} \mathrm{C}$ for $4 \mathrm{~h}$ (Ruan et al., 2001), hereinafter referred to as S-AA.

\section{Pot Experiment}

The experiment was conducted at the experimental site of the Institute of Radix Angelicae Sinensis in Minxian County, Gansu province in China, during the growing season of 2008. The average temperatures for day and night were 24 and $13^{\circ} \mathrm{C}$, respectively and the light and dark periods were 14 and $10 \mathrm{~h}$ each day during the whole growing season, respectively.

Ten $\mathrm{kg}$ of soil samples was put into plastic pots $(30 \times 30 \times 28 \mathrm{~cm})$, respectively the soil samples include three tupes, that is CK, AA and S-AA, respectively. The soil moisture content was raised to $70 \%$ of water holding capacity by adding tap water, then the pots were embedded into the soil remaining the up of pot was same height with the ground for eliminating affected by the external conditions using a completely randomized design. $A$. sinensis seedlings were transplanted into each pot on 24 March, and thinned to 4 seedlings/pot at $7 \mathrm{~d}$ after they emergence.

\section{Sampling}

At 8 May, 23 June and 4 August the stem height was measured to the tip of the youngest visible leaf. At seedling stage (23 June), healthy leaves of $A$. sinensis were collected, and transported to the laboratory in ice-coolers and stored at $4{ }^{\circ} \mathrm{C}$ until analyzed. The yield and quality was determined at the harvest stage ( 25 October).
At rootstock thickening (15 August), the soil adhering to the root, designated as 'rhizosphere soil' (Fujii et al., 2005), was collected, and the soil samples were mixed, sieved through a 1-mm mesh sieve. The soil samples were transported to the laboratory in ice-coolers and stored at $4{ }^{\circ} \mathrm{C}$ until analyzed. Care was taken during sampling to prevent cross-contamination of the soils.

\section{Antioxidant Enzyme Activity Determination in Leaves}

Antioxidant enzyme extraction and activity determination were carried out following the method of Zhang et al (2015b). Generally, each $0.5 \mathrm{~g}$ of leaf material was homogenized with extraction buffer containing $50 \mathrm{mM}$ phosphate buffer (pH 7.4), 1 mM EDTA, $1 \mathrm{~g}$ PVP and $0.5 \%$ $(\mathrm{v} / \mathrm{v})$ Triton $\times 100$. The homogenate was centrifuged for 20 $\min$ at $12,000 \mathrm{~g}$ and the supernatant obtained was used for enzyme analysis. All operations were carried out at $0-4^{\circ} \mathrm{C}$.

Superoxide dismutase (SOD) activity was measured by its ability to inhibit the photochemical reaction of $N B T$ at $560 \mathrm{~nm}$ (Zhang et al., 2013). One unit of SOD activity was defined as the enzyme amount causing $50 \%$ inhibition of $N B T$ reduction. SOD activity is expressed as units per $\mathrm{mg}$ FM of leaves.

Peroxidase (POD) activity was measured by monitoring the increase in absorbance at $470 \mathrm{~nm}$ due to guaiacol oxidation at $25^{\circ} \mathrm{C}$ (Zhang et al., 2013). One unit of POD activity was defined as the increase in absorbance at $470 \mathrm{~nm}$ for $1 \mathrm{~min}$ due to guaiacol oxidation. POD activity expressed as units per min per $\mathrm{g}$ fresh mass (FM).

Catalase (CAT) activity was assayed by monitoring the disappearance of $\mathrm{H}_{2} \mathrm{O}_{2}$ at $240 \mathrm{~nm}$ at $25^{\circ} \mathrm{C}$ (Zhang et al., 2013). One unit of CAT activity was defined as the decrease at $240 \mathrm{~nm}$ for $1 \mathrm{~min}$ due to $\mathrm{H}_{2} \mathrm{O}_{2}$ consumption. CAT activity expressed as units per min per g FM. MDA concentrations were measured using the Thiobarbituric acid (TBA) test (Zhang et al., 2013).

\section{Enumeration of Culturable Microbial Populations in Rhizosphere Soil}

Enumeration of cultivable microbial populations was determined with traditional plate-dilution frequency technique on agar media in Petri plates (Harris and Sommers, 1968). Well mixed $0.1 \mathrm{~mL}$ samples of dilutions from $10^{-3}$ to $10^{-7}$ (in sterile deionized water) were spread in triplicate onto the following media for cultivable microbe enumerations. Bacteria was determined in the culture medium of Beef-cream and Peptone. Actinomycete was determined in the culture medium of improved Gao 1, and fungi was determined in that of Martin's agar. Azobacter was determined in agar according to Ashby, and aerobic cellulose-decomposing bacteria was determined in agar according to Waksman. Ammonifying bacteria was determined in the culture medium of protein agar medium, and organic phosphorussolubilizing bacteria was determined in that of Meng 
Jina's agar. Inorganic phosphorus-solubilizing bacteria was determined in the culture medium of calcigenol simple and glucose, and kalium-solubilizing bacteria was determined in that of potassium aluminium silicate agar (Zhang et al., 2015b).

\section{Analysis of Functional Group Diversity in Rhizosphere Soil}

The characteristic parameters including abundance, community diversity and evenness, and dominance concentration were calculated according to the type and amount of functional group (Zhang et al., 2015a):

(1) Abundance $\left(\mathrm{P}_{\mathrm{i}}\right)$ was calculate by Berger-Parker method as $P_{i}=N_{i} / N$, where $N_{i}$ represent the number of individuals in a cluster (or species) divided by the total number of isolates in the sample being analyzed. When $\mathrm{P}_{\mathrm{i}}>0.10$ as dominant groups, $0.01<\mathrm{P}_{\mathrm{i}} \leq 0.10$ as common groups, $\mathrm{P}_{\mathrm{i}} \leq 0.01$ as scarce groups.

(2) Community Diversity $(\mathrm{H})$ was calculate by Shannon-Wiener method as $\mathrm{H}=-\sum_{i=1}^{n} P i \ln P i$, where $P_{i}$ represent the proportion of individuals of given species.

(3) Community Evenness (J) was calculate by Pielou method as $\mathrm{J}=\mathrm{H} / \mathrm{lnS}$, where $\mathrm{H}$ represent the diversity of microbe community, $\mathrm{S}$ stand for the species number in soil microbe communities.

(4) Dominance Concentration (C) was calculate by Pielou method as $\mathrm{C}=\sum \mathrm{Pi}^{2}$, where $P_{i}$ represent the proportion of individuals of given species.

\section{Statistical Analysis}

All experimental data were analysed by ANOVA using SPSS 17.0 software (SPSS Inc., USA) and significant differences were tested using the Least Significant Differences (LSD) test at $P \leq 0.05$. Mean values and standard errors (SE) were presented.

\section{Results}

\section{Plant Growth Parameters of $\boldsymbol{A}$. sinensis}

Plant height: As shown in Fig. 1A, plant height of $A$. sinensis in continuous cropping treatment was significantly decreased compared to the control at each measured stage. However, effect of soil sterilization on plant height of $A$. sinensis was different with the growth stage. Specifically, the plant height was significantly decreased in continuous cropping by sterilization at the first measured stage, but a significant increase occurred at latter two measured stages.

Plant dry weight: This study indicated that continuous cropping reduced shoot dry weight by $35.42 \%$ and root dry weight by $15.70 \%$ at rootstock thickening stage (Fig. 1B), as compared to control. However, sterilization treatment increased shoot dry weight by $54.83 \%$ and root dry weight by $13.72 \%$, as compared to continuous cropping.

Yield and quality: This study indicated that continuous cropping decreased the yield, content of essential oils and alcohol-soluble extract by $39.44 \%, 34.15 \%$ and $12.33 \%$ (Table 2), as compared to control. However, soil sterilization treatment increased the yield, content of essential oils and alcohol-soluble extract by $43.52 \%, 31.48 \%$ and $7.53 \%$, respectively (Table 2), as compared to continuous cropping, which close to the control.

\section{Antioxidant Enzyme Activity and Lipid Peroxidation in Leaves of $A$. sinensis}

Compared with control, continuous cropping was found to significantly decrease the activity of SOD and POD in leaves of $A$. sinensis, but significantly increase the activity of CAT and the content of MDA. However, soil sterilization treatment significantly increased the activity of SOD and POD, decreased the activity of CAT and the content of MDA (Table 3), as compared to continuous cropping. This indicated that soil sterilization could change antioxidant enzyme activity and lipid peroxidation in leaves of $A$. sinensis in a continuous mono-cropping soil.

\section{Enumeration of Culturable Microbial Populations in Rhizosphere soil of $A$. sinensis}

As shown in Fig. 2A, the number of culturable fungi of continuous $A$. sinensis cropping soil was significantly greater than that of the control soil at rootstock thickening stage, increased by $22.79 \%$ compared to the control. However, the number of culturable actinomycete of continuous $A$. sinensis cropping soil was significantly lower than that of the control soil, decreased by $29.79 \%$ compared to the control, and the number of bacteria was not significant difference in continuous $A$. sinensis cropping soil and control.

The number of fungi and actinomycete in sterilized soil was decreased by $52.87 \%$ and $81.83 \%$, respectively, compared with those in non-sterilized soil. In addition, bacteria were slightly enhanced (Fig. 2A).

\section{Enumeration of Bacteria Functional Groups in Rhizosphere Soil}

This study indicated that continuous $A$. sinensis changed the number of bacteria functional groups in rhizosphere soil of A. sinensis. The number of ammonifying bacteria was significantly greater than that of the control, increasing by 96.48\% compared to the control (Fig. 2B). Contrarily, the number of aerobic cellulose-decomposing bacteria, organic phosphorus-solubilizing bacteria, inorganic phosphorussolubilizing bacteria and kalium-solubilizing bacteria in continuous $A$. sinensis cropping soil was decreased by $44.01,47.19,71.43$ and $21.72 \%$, respectively compared with those in the control soil. 
Table 1: The physiochemical properties of soil samples for pot experiment

\begin{tabular}{lllllll}
\hline $\begin{array}{l}\text { Soil sample } \\
\text { type }\end{array}$ & $\begin{array}{l}\text { Organic } \\
\text { matter }(\%)\end{array}$ & $\begin{array}{l}\text { Total N content } \\
\left(\mathrm{g} \mathrm{kg}^{-1}\right)\end{array}$ & $\begin{array}{l}\text { Total K concentration } \\
\left(\mathrm{g} \mathrm{kg}^{-1}\right)\end{array}$ & $\begin{array}{l}\text { Total P concentration } \\
\left(\mathrm{g} \mathrm{kg}^{-1}\right)\end{array}$ & $\begin{array}{l}\text { Available } \mathrm{N} \\
\text { concentration }\left(\mathrm{mg} \mathrm{kg}^{-1}\right)\end{array}$ & $\begin{array}{l}\text { Available P concentration } \\
\left(\mathrm{mg} \mathrm{kg}^{-1}\right)\end{array}$ \\
\hline AA & 0.66 & 0.89 & 20.74 & 1.15 & 29.26 & 15.84 \\
CK & 0.66 & 0.96 & 21.89 & 1.24 & 32.45 & 15.38 \\
\hline
\end{tabular}

Table 2: Effect of soil sterilization on root yield and quality of $A$. sinensis in a continuous mono-cropping soil

\begin{tabular}{llll}
\hline Treatment & Root yield $\left(\mathrm{g} \cdot\right.$ pot $\left.^{-1}\right)$ & Essential oils content $(\%)$ & Alcohol-soluble extract $(\%)$ \\
\hline CK & $47.71 \pm 3.97^{\mathrm{a}}$ & $0.82 \pm 0.06^{\mathrm{a}}$ & $57.45 \pm 2.18^{\mathrm{a}}$ \\
AA & $27.04 \pm 4.94^{\mathrm{c}}$ & $0.55 \pm 0.06^{\mathrm{b}}$ & $50.35 \pm 2.80^{\mathrm{b}}$ \\
S-AA & $37.59 \pm 2.56^{\mathrm{b}}$ & $0.71 \pm 0.08^{\mathrm{a}}$ & $54.33 \pm 1.57^{\mathrm{ab}}$ \\
\hline
\end{tabular}

Lines in columns denoted by different letters are significantly at $P<0.05$ according to least significant difference tests

Table 3: Effect of soil sterilization on antioxidant enzyme activity and lipid peroxidation of $A$. sinensis leave in a continuous mono-cropping soil

\begin{tabular}{lllll}
\hline Treatment & SOD activity $\left(\mathrm{U} \cdot \mathrm{mg}^{-1} \mathrm{FM}\right)$ & POD activity $\left(\mathrm{U} \cdot \mathrm{min}^{-1} \cdot \mathrm{g}^{-1} \mathrm{FM}\right)$ & CAT activity $\left(\mathrm{U} \cdot \mathrm{min}^{-1} \cdot \mathrm{g}^{-1} \mathrm{FM}\right)$ & MAD content $\left(\mu \mathrm{mol} \cdot \mathrm{g}^{-1} \mathrm{FM}\right)$ \\
\hline CK & $1.03 \pm 0.10^{\mathrm{a}}$ & $20.13 \pm 1.20^{\mathrm{a}}$ & $72.66 \pm 5.66^{\mathrm{b}}$ & $2.36 \pm 0.07^{\mathrm{c}}$ \\
AA & $0.65 \pm 0.05^{\mathrm{b}}$ & $6.53 \pm 0.44^{\mathrm{b}}$ & $100.39 \pm 9.03^{\mathrm{a}}$ & $2.73 \pm 0.04^{\mathrm{a}}$ \\
S-AA & $0.96 \pm 0.07^{\mathrm{a}}$ & $19.58 \pm 0.92^{\mathrm{a}}$ & $64.81 \pm 3.71^{\mathrm{b}}$ & $2.57 \pm 0.07^{\mathrm{b}}$ \\
\hline
\end{tabular}

Lines in columns denoted by different letters are significantly at $P<0.05$ according to least significant difference tests

Table 4: Effect of soil sterilization on parameters of bacterial functional groups diversity in rhizosphere soil of $A$. sinensis in a continuous mono-cropping soil

\begin{tabular}{|c|c|c|c|c|c|c|c|c|c|}
\hline \multirow[t]{2}{*}{ Treatment } & \multicolumn{5}{|c|}{ Abundance $\left(\mathrm{P}_{\mathrm{i}}\right)$} & \multirow{2}{*}{$\begin{array}{l}\text { Total individual } \\
\text { No. }(\mathrm{N}) \times 10^{4}\end{array}$} & \multirow{2}{*}{$\begin{array}{l}\text { Community } \\
\text { diversity }(\mathrm{H})\end{array}$} & \multirow{2}{*}{$\begin{array}{l}\text { Evenness } \\
\text { (J) }\end{array}$} & \multirow{2}{*}{$\begin{array}{l}\text { Concentration } \\
\text { (C) }\end{array}$} \\
\hline & $\mathrm{AB}$ & $\mathrm{ACDB}$ & OPSB & IPSB & KSB & & & & \\
\hline CK & 0.7885 & 0.1678 & 0.0092 & 0.0212 & 0.0132 & 13.68 & 0.6691 & 0.4157 & 0.6507 \\
\hline AA & 0.9308 & 0.0564 & 0.0029 & 0.0036 & 0.0062 & 22.78 & 0.2981 & 0.1852 & 0.8696 \\
\hline S-AA & 0.8661 & 0.1056 & 0.0070 & 0.0114 & 0.0100 & 10.56 & 0.4934 & 0.3066 & 0.7615 \\
\hline
\end{tabular}

Where AB: Ammonifying bacteria; ACDB: Aerobic cellulose-decomposing bacteria; OPSB: Organic phosphorus-solubilizing bacteria; IPSB: Inorganic phosphorus-solubilizing bacteria; KSB: Kalium-solubilizing bacteria

The number of ammonifying bacteria and kaliumsolubilizing bacteria in sterilized soil was significantly decreased by 56.93 and $25.56 \%$, respectively compared with those in non-sterilized soil of continuous $A$. sinensis cropping, however, the number of inorganic phosphorussolubilizing bacteria was significantly increased by $44.28 \%$, and the number of aerobic cellulose-decomposing bacteria and organic phosphorus-solubilizing bacteria was slightly changed.

\section{Analysis of Functional Group Diversity in Rhizosphere Soil}

The abundance of aerobic cellulose-decomposing bacteria, inorganic phosphorus-solubilizing bacteria and kaliumsolubilizing bacteria in rhizosphere soil of continuous $A$. sinensis cropping changed compared with the control. Although the total population of functional groups in continuous $A$. sinensis cropping rhizosphere soils was higher than in control soil, $\mathrm{H}$ and $\mathrm{J}$ were decreased by $55.45 \%$ and $55.45 \%$, respectively whereas $\mathrm{C}$ was increased by $33.64 \%$ (Table 4 ).

Abundance of all bacteria functional groups determined, total individual number, $\mathrm{H}, \mathrm{J}$ and $\mathrm{C}$ in sterilized soil of continuous $A$. sinensis cropping changed markedly compared with in non-sterilized soil of continuous $A$. sinensis cropping, which tend to close those in control soil.

\section{Discussion}

Soil sterilization could improve growth of $A$. sinensis plants at the later growth stage to greater extent under continuous cropping, and for example, plant height, dry weight, yield and quality of $A$. sinensis plants grown in sterilized soil were significantly higher than those in non-sterilized soil, this is consistent with the results of cucumber (Ruan et al., 2001), apple (Leinfelder and Merrin, 2006), pepper (Hou et al., 2006) and soybean (Zhang et al., 2007). We believe that growth retardation of plant grown in sterilized soil appeared at the early growth stage is due to the fact that microorganisms which played an important role to in nutrient transformation, which were killed by soil sterilization. Soil microbial communities rapidly re-colonize in sterilized soil, and during re-colonization, the community structure changed rapidly with a general trend towards higher diversity and evenness (Marschner and Rumberger, 2004; Yim et al., 2013). Soil sterilization eliminated soilborne pathogens, also increased availability and acquisition of nutrients (Troelstra et al., 2001; Costa et al., 2006), with the result that plant growth of $A$. sinensis was improved at later growth stage. 

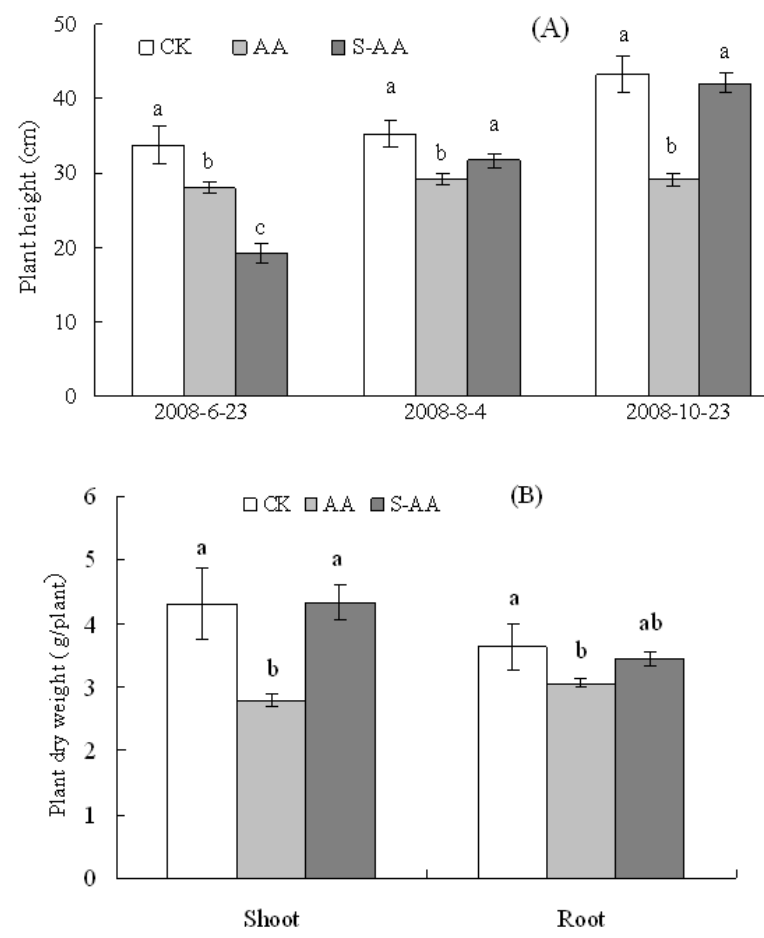

Fig. 1: Effect of soil sterilization on plant height (A) and biomass (dry weight, g) (B) of A. sinensis in a continuous mono-cropping soil. Within each growth stage or each plant component, vertical bars (s.e.) with the same letter are not significantly different $(P<0.05)$

In general, plants generate more ROS and stimulate resistance responses when exposed to stressful conditions (Hancock et al., 2002; Thoma et al., 2003). Plant possess efficient systems for scavenging ROS that protect them from destructive oxidative reactions (Olmos et al., 1994). Anti-oxidative enzymes are the most important components in the scavening system of ROS. The activity of antioxidant enzymes has reported to decrease under continuous cropping of cucumber (Zhang et al., 2007) and grape (Guo et al., 2010), but increases in pepper (Hou et al., 2006).

The effect of sterilized replant soil on the antioxidant enzymes under continuous cropping stress has been reported by Zhang (Zhang et al., 2007 ) who has described increases in activity of SOD, POD, CAT in mono-continuous cropping cucumber leaves and an increase in SOD activity in continuous cropping grape leaves (Guo et al., 2010). However, decreases in activity of SOD and POD in continuous cropping pepper leaves and roots (Hou et al., 2006). The results of the present experiment showed that the activity of SOD and POD in mono-continuous cropping stressed $A$. sinensis leaves was increased by steam sterilization, however, a decrease in CAT activity was observed. This suggests that in sterilized soil, the stressful condition of continuous cropping was alleviated and making ROS maintain lower levels, so that CAT activities remain a low level. This is consistent with the results of other crops (Lechno et al., 1997; Posmyk et al., 2005).
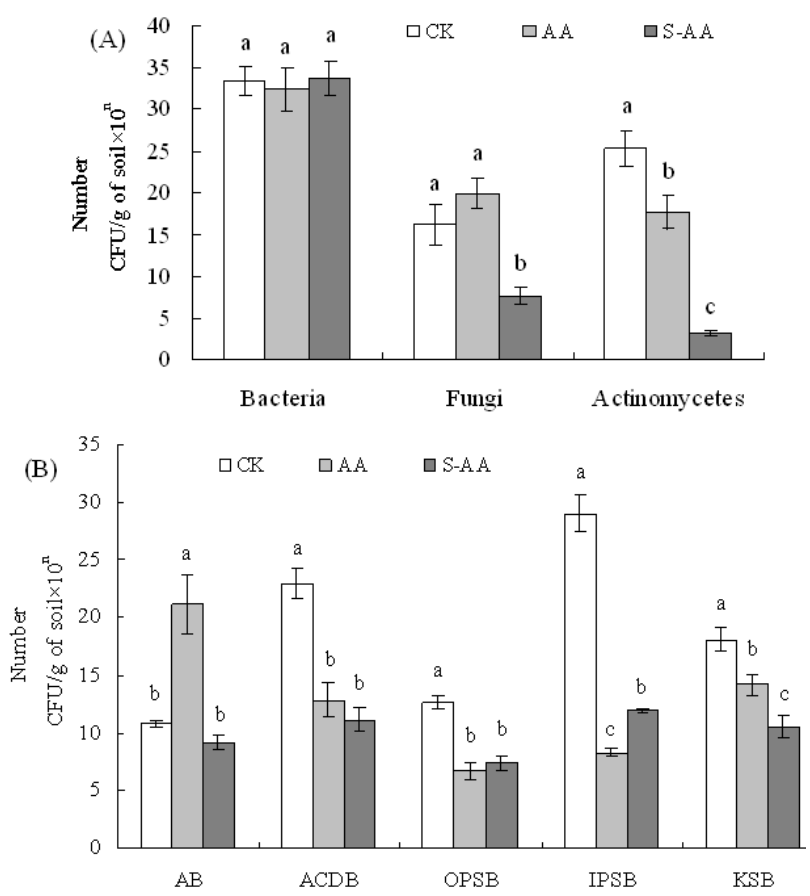

Fig. 2: Effect of soil sterilization on population of microorganisms (A) and populations of bacteria functional groups in rhizosphere soil (B) in a continuous monocropping soil. Within each population, vertical bars (s.e.) with the same letter are not significantly different $(P<0.05)$. Where AB: Ammonifying bacteria; ACDB: Aerobic cellulose-decomposing bacteria; OPSB: Organic phosphorus-solubilizing bacteria; IPSB: Inorganic phosphorus-solubilizing bacteria; KSB: Kaliumsolubilizing bacteria

Note: Bacteria: $\mathrm{CFU} / \mathrm{g}$ of soil $\times 10^{5}$, Fungi. $\mathrm{CFU} / \mathrm{g}$ of soil $\times 10^{2}$, Actinomycetes. CFU/g of soil $\times 10^{5}$. AB, CFU/g of soil $\times 10^{4}$; ACDB, $\mathrm{CFU} / \mathrm{g}$ of soil $\times 10^{3}$; OPSB, CFU/g of soil $\times 10^{2}$; IPSB, CFU/g of soil $\times 10^{2}$; $\mathrm{KSB}, \mathrm{CFU} / \mathrm{g}$ of soil $\times 10^{2}$. Where $\mathrm{CFU}$ : Colony forming units

Soil microorganisms play an important role in the soil ecosystem, and to a certain extent, soil microbial community composition and changes in types or amounts of soil microorganisms can reflect changes in soil quality (Jiao and $\mathrm{Wu}, 2004)$. Microorganisms are also the key to overcome problems associated with continuous cropping and other agricultural practices that detrimentally affect soil health (Liu et al., 2010). Further, different diversity indices can reflect better functional of the soil microbial community as affected by soil management. In our study, continuous cropping changes the amount of soil microorganisms and decreases the diversity of bacteria functional groups. This is consistent with the results of Hartmann and Widmer (2006). The result demonstrated that continuous cropping systems have negative effects on soil microbial communities.

Soil sterilization can alleviate the effects of continuous cropping, and improve the ability of plants to adapt to continuous cropping (Zhang et al., 2007). The results of our study indicate that soil sterilization can relieve the 
detrimental effects of continuous cropping on the quantity and diversity of microorganisms in rhizosphere soil of $A$. sinensis plants, with the result that detrimental effects of continuous cropping was alleviated. This indicated that soil sterilization could as a possible method to eliminate the continuous cropping problem in $A$. sinensis in the controlled experiment condition. However, in the field, for examplesoil microbial recovery after sterilization treatments was affected by communities escaped from the treatment, by microbes of deep layers, by those of nearby soils. Therefore, further experiment should to be conducted in the field condition.

\section{Acknowledgements}

This work is supported by Natural Science Foundation of China (31060182 and 31260304).

\section{References}

Benizri, E., S. Piutti, S. Verger, L. Pagès, G. Vercambre, J.L. Poessel and P. Michelot, 2005. Replant diseases: bacterial community structure and diversity in peach rhizosphere as determined by metabolic and genetic fingerprinting. Soil Biol. Biochem., 37: 1738-1746

Champakaew, D., A. Junkum, U. Chaithong, A. Jitpakdi, D. Riyong, R. Sanghong, J. Intirach, R. Muangmoon, A. Chansang, B. Tuetun and B. Pitasawat, 2015. Angelica sinensis (Umbelliferae) with proven repellent properties against Aedes aegypti, the primary dengue fever vector in Thailand. Parastol. Res., 114: 2187-2198

Chen, C.Y., 2002. Trace elements in Taiwanese health food, Angelica keiskei, and other products. Food Chem., 84: 545-549

Costa, R., M. Götz, N. Mrotzek, J. Lottmann, G. Berg and K. Smalla, 2006. Effects of site and plant species on rhizosphere community structure as revealed by molecular analysis of microbial guilds. FEMS Microbiol. Ecol., 56: 236-249

Fujii, Y., A. Furubayashi and S. Hiradate, 2005. Rhizosphere soil method: a new bioassay to evaluate allelopathy in the field. In: Proceedings of the Fourth World Congress on Allelopathy 'Establishing the Scientific Base', pp: 490-492. Haper, J.D.I., M. An and J.H. Kent (eds.), Charles Sturt University, Wagga, NSW, Australia

Guo, X.W., K. Li, H.G. Xie, Y.N. Sun, X.X. Hu and L.H. Zhang, 2010 Effect of sterilized replant soil on grape growth and root exudation characteristics. J. Fruit Sci., 27: 29-33

Hancock, J.T., R. Desikan, A. Clarke, R.D. Hurst and S. Neill, 2002. Cell signalling following plant/pathogen interactions involves the generation of reactive oxygen and reactive nitrogen species. Plant Physiol. Biochem., 40: 611-617

Harris, R.F. and L.E. Sommers, 1968. Plate-dilution frequency technique for assay of microbial ecology. J. Appl. Microbiol., 16: 330-334

Hartmann, M. and F. Widmer, 2006. Community structure analyses are more sensitive to differences in soil bacterial communities than anonymous diversity indices. Appl. Environ. Microbiol., 72: 7804 7812

Hassan, M.S., A.H. El-Behadli and I.S. Alsaadawi, 1989. Citrus replant problem in Iraq. I . Possible role of soil fungi and nematodes. Plant Soil, 116: 151-155

Hou, Y.X., B.L. Zhou, X.L. Wu, Y.W. Fu and Y.Y. Wang, 2006. Effects of soil sterilization on preventing continuous pepper cropping obstacles. Chin. J. Ecol., 25: 340-342

Jiao, X.D. and F.Z. Wu, 2004. Progress of the methods for studying soil microbial diversity. Chin. J. Soil Sci., 35: 789-793

Lechno, S., E. Zamski and E. Telor, 1997. Salt stress-induced responses in cucumber plants. J. Plant Physiol., 150: 206-211

Leinfelder, M.M. and L.A. Merwin, 2006. Rootstock selection, preplant soil treatments, and tree planting positions as factors in managing apple replant disease. HortScience, 41: 394-401

Liu, J., F.Z. Wu and Y. Yang, 2010. Effects of cinnamic acids on bacterial community diversity in rhizosphere soil of cucumber seedlings under salt stress. Agric. Sci. Chin., 9: 266-274
Marschner, P. and A. Rumberger, 2004. Rapid changes in the rhizosphere bacterial community structure during re-colonization of sterilized soil. Biol. Fert. Soils, 40: 1-6

Mazzola, M. and L.M. Manici, 2012. Apple replant disease: role of microbial ecology in cause and control. Annu. Rev. Phytopathol., 50: $45-65$

Olmos, E., J.A. Hernandez, F. Sevilla and E. Hellin, 1994. Induction of several antioxidant enzymes in the selection of a salt-tolerant cell line of Pisum sativum. J. Plant Physiol., 144: 594-598

Posmyk, M.M., C. Bailly, K. Szafrańska, K.M. Janas and F. Corbieau, 2005. Antioxidant enzymes and isoflavonoids in chilled soybean (Glycine $\max ($ L.) Merr.) seedlings. J. Plant Physiol., 162: 403-412

Ruan, W.B., J.G. Wang, F.S. Zhang, X.M. Li, Y.F. Wang and Q.R. Su, 2001 Effect of sterilization with $\mathrm{CH}_{3} \mathrm{Br}$ on root growth of soybean seedlings. Acta Ecol. Sin., 21: 759-764

Troelstra, S.R., R. Wagenaar, W. Smant and B.A.M. Peters, 2001. Interpretation of bioassays in the study of interactions between soil organisms and plants: involvement of nutrient factors. New Phytol., 150: 697-706

Thoma, I., C. Loeffler, A.K. Sinha, M. Gupta, M. Krischke, B. Steffan, T. Roitsch and M.J. Mueller, 2003. Cyclopentenone isoprostanes induced by reactive oxygen species trigger defense gene activation and phytoalexin accumulation in plants. Plant J., 34: 363-375

Wu, F.Z., X.Z. Wang and C.Y. Xue, 2009. Effect of cinnamic acid on soil microbial characteristics in the cucumber rhizosphere. Eur. J. Soil Biol., 45: 356-362

Yang, J.I., P.M. Ruegger, M.V. McKenry, J.O. Becker and J. Borneman, 2012. Correlations between root-associated microorganisms and peach replant disease symptoms in a California soil. PLoS One, 7: e46420

Yang, Y.H., M.J. Li, X.J. Chen, P.F. Wang, F.Q. Wang, W.X. Lin, Y.J. Yi, Z.W. Zhang and Z.Y. Zhang, 2014. De novo characterization of the Rehmannia glutinosa leaf transcriptome and analysis of gene expression associated with replanting disease. Mol. Breed., 34: 905915

Yao, H.Y., X.D. Jiao and F.Z. Wu, 2006. Effects of continuous cucumber cropping and alternative rotations under protected cultivation on soil microbial community diversity. Plant Soil, 284: 195-203

Yim, B.L., K. Smalla and T. Winkelmann, 2013. Evaluation of apple replant problems based on different soil disinfection treatments-links to soil microbial community structure. Plant Soil, 366: 617-631

Yu, J.Q. and Y. Matsui, 1994. Phytotoxic substances in root exudates of cucumber (Cucumis sativus L.). J. Chem. Ecol., 20: 21-31

Zhang, S.Y. and K.C. Cheng, 1989. Medicinal and aromatic plants. In: Biotechnology in Agriculture and Forestry. Bajaj, Y.P.S. (ed.) Springer, Heidelberg, Germany

Zhang, X.H., E.H. Zhang and H.Z. Wang, 2009. Effect of continuous cropping on the essential oils of Angelica sinensis. Nat. Prod. Res. Dev, 21: 342-346

Zhang, X.H., E.H. Zhang, X.Y. Fu, Y. Huang and D.Y. Lang, 2010. Autotoxic effects of Angelica sinensis (Oliv.) Diels. Allelopathy J. 26: $1-12$

Zhang, Z., W. Lin, Y. Yang, H. Chen and X. Chen, 2011. Effects of continuous cropping Rehmannia glutinosa $\mathrm{L}$. on diversity of fungal community in rhizospheric soil. Agric. Sci. Chin., 10: 1374-1384

Zhang, X.H., D.Y. Lang, E.H. Zhang, C.C. Bai and H.Z. Wang, 2013. Diurnal changes in photosynthsis and antioxidants of Angelica sinensis as influenced by cropping systems. Photosynthetica, 51: $252-258$

Zhang, X.H., D.Y. Lang and E.H. Zhang, 2015a. Effect of intercropping of Angelica sinensis with garlic on its growth and rhizosphere microflora. Int. J. Agric. Biol., 17: 554-560

Zhang, X.H., D.Y. Lang, E.H. Zhang and Z.S. Wang, 2015b. Effect of autotoxicity and soil microbes in continuous cropping soil on Angelica sinensis seedling growth and rhizosphere soil microbial population. Chin. Herb. Med., 7: 88-93

Zhang, S.S., X.M. Yang, Z.S. Mao, Q.W. Huang, Y.C. Xu and Q.R. Shen, 2007. Effects of sterilization on growth of cucumber plants and soil microflora in a continuous mono-cropping soil. Acta Ecol. Sin., 27: 1809-1817

Zhao, C.F., H. Liu and L.J. Yu, 2010. The effect of continuous cropping to soil bacterial community on Liriope root. Microbiol. Chin., 37: 487491

(Received 16 February 2015; Accepted 26 October 2015) 